\title{
Người chuyển giới và hoạt động kinh doanh tại Việt Nam
}

\author{
Hồ Mạnh Toàn \\ SSHPA System \\ E-mail: toan@sshpa.com
}

Hà Nội, 03-12-2018

SSHPA - (25-06-2018; Cập nhật bổ sung từ bài giới thiệu nghiên cứu mới trên SSHPA: https://sc.sshpa.com/post/4207) - Nền tảng văn hóa Việt Nam tạo nên bởi các giá trị Tam giáo [1,2,3] và trong bối cảnh hiện đại, các giá trị này có ảnh hưởng lớn đến nhận thức, hành vi của người Việt trong nhiều vấn đề như kinh tế [2, 3] hay giới tính [4].

Hai tác giả Pauline Oosterhoff (University of Sussex, Anh) và Hoàng Tú Anh (Center for Creative Initiatives in Health and Population - CCIHP, Hà Nội) đã công bố nghiên cứu bàn về người chuyển giới và hoạt động kinh doanh tại Việt Nam [5].

Nghiên cứu điều tra về cơ hội cũng như khó khăn kinh tế mà các nhân viên chuyển giới gặp phải trong môi trường tại Việt Nam. Hai tác giả đã sử dụng bản khảo sát gồm 29 câu hỏi để khảo sát 334 người chuyển giới $(77.5 \%$ là người chuyển giới nam và $22.5 \%$ là người chuyển giới nữ) để điều tra lựa chọn và sở thích về việc làm cũng như mối liến kết giữa sự kì thị, giáo dục và công việc.

Kết quả cho thấy các quan niệm và tiêu chuẩn về giới tính thông thường dẫn đến sự bất bình đẳng về kinh tế giữa nam chuyển giới và phụ nữ chuyển giới. Ví dụ phụ nữ chuyển giới cảm thấy có những gánh nặng từ sự kỳ vọng về trách nhiệm tài chính và hỗ trợ gia đình mà nam chuyển giới không gặp phải. Tuy nhiên, bất chấp sự khó khăn thì vẫn có những thành công đến với người chuyển giới.

Hai nhà nghiên cứu cuối cùng nhấn mạnh tầm quan trọng của các doanh nghiệp vừa và nhỏ trong việc tạo ra công việc hợp pháp và hài lòng cho người chuyển giới.

Có thể nói, các hoạt động kinh tế sôi động không chỉ thúc đẩy, phát triển đất nước mà còn đã và đang thay đổi các quan niệm cũ và mang đến những cơ hội mới cho các nhóm người yếu thế trong xã hội. Trước đó, một số nghiên cứu khác cũng đã chỉ ra khởi nghiệp đã mang đến những cơ hội cải thiện đời sống và bản thân cho người phụ nữ $[6,7]$, vốn cũng bị những quan niệm truyền thống ảnh hưởng $[8,9]$.

Tuy nhiên, thực tế xã hội hiện nay vẫn còn nhiều ý kiến cổ hủ, tiêu cực về vấn đề giới tính. Chính vì thế, bên cạnh các hoạt động cộng đồng, các nghiên cứu sâu về các nhóm đối tượng này là cần thiết để bổ sung thêm những góc nhìn khoa học, khách quan cho các hoạt động cộng đồng thực tiễn. 


\section{References:}

[1] Vuong Q. H., La V. P., Vuong T. T., Nguyen V. H., Ho M. T., Nguyen T. H. K., Bui Q. K., Ho M. T. (2018). Cultural additivity: Behavioural insights from the interaction of Confucianism, Buddhism, and Taoism in folktales. Palgrave Communications, 4, DOI: 10.1057/s41599-018-0189-2. URL: https://www.nature.com/articles/s41599-018-0189-2.

[2] Vuong Q. H., Tran T. D. (2009). The cultural dimensions of the Vietnamese private entrepreneurship. IUP Journal of Entrepreneurship Development, VI(3-4): 5478.

[3] Vuong, Q. H. (2016). Impacts of geographical locations and sociocultural traits on the Vietnamese entrepreneurship. SpringPlus, 5, 1189, DOI: 10.1186/s40064016-2850-9.

[4] Le, T. M. \& Yu, N. (2018). Ideological and philosophical underpinnings of attitudes toward sexual minorities in Vietnamese society. Sexuality \& Culture, DOI: 10.1007/s12119-018-9577-4.

[5] Oosterhoff, P., \& Hoang, T. A. (2018). Transgender employment and entrepreneurialism in Vietnam. Gender \& Development, 26(1), 33-51, DOI: $10.1080 / 13552074.2018 .1429102$.

[6] Poon, J. P., Thai, D. T., \& Naybor, D. (2012). Social capital and female entrepreneurship in rural regions: Evidence from Vietnam. Applied Geography, 35(1-2), 308-315.

[7] Le, Q. V., \& Raven, P. V. (2015). Woman entrepreneurship in rural Vietnam: Success and motivational factors. The Journal of Developing Areas, 49(2), 57-76.

[8] Thao, N. T. P., Hong, K. T., \& Le, B. D. (2011). 'A Real Man Must be Active, a Real Woman Must be Submissive': The Discourse of Sexuality in Today's Vietnam. Culture Health \& Sexuality, 13, S22-S23.

[9] Hong, K. T. (2016). Women and development in Vietnam: Caught between social tradition and economic globalization. Regions and Cohesion, 6(2), 110-119. 